\title{
COMPUTER MODELING AND ANALYSIS OF THE ENERGY-POWER PROCESS PARAMETERS OF THE COMBINED MACHINING OF ALLOYS AI-Mg SYSTEM
}

\author{
Sergey SIDELNIKOV ${ }^{1}$, Anton SAMCHUK ${ }^{1}$, Denis VOROSHILOV ${ }^{1, \mathrm{a}}$ *, \\ Yuriy GORBUNOV ${ }^{1}$, Vladimir BER ${ }^{1}$, Roman GALIEV ${ }^{1}$, \\ Ruslan SOKOLOV ${ }^{1}$, Vadim BESPALOV ${ }^{1}$ \\ ${ }^{1}$ Siberian Federal University, Russia, 660025, Krasnoyarsk, Krasnoyarskiy Rabochiy ave., 95 \\ ae-mail: sibdrug@mail.ru
}

Keywords: aluminum alloys, magnesium, combined machining, rolling-extrusion, temperature, strain rate, drawing ratio, energy-power parameters.

\begin{abstract}
Article shows the results of studies of the process of combined rolling-extruding of an alloy of the Al-Mg system (AMg6) under various temperature-speed and deformation conditions. Calculations shows that with increasing metal temperature at the entrance to the deformation center, the values of the forces on the rolls and the die decrease, the increase in drawing leads to an increase in the values of forces on both the rolls and the die, and an increase in the deformation rate leads to hardening of the metal and increasing energy parameters of the process of combined machining. However, the maximum extruding force on the combined machining units is 5-10 times lower than the efforts to obtain the same press products on hydraulic presses. A computer model of the combined machining process was created and with the help of the DEFORM 3D complex, the analysis of the metal flow, the temperature distribution of the metal over the section of the workpiece was carried out when producing round bars of different diameters. Shaping of the metal corresponds to the data of experimental and theoretical studies, while the deformation center has a characteristic appearance, including the gripping zones of the workpiece and its rolling, repressing and extrusion. The peculiarity for this alloy is that with a drawing ratio of $\mu=3.7$ and a strain rate of $\xi=0.78 \mathrm{~s}^{-1}$, the steady extruding process takes place without completely filling the deformation zone from the side of the roll with a protrusion. An increase in drawing ratio or strain rate leads to a decrease in the contactless zone or to its absence. The change in metal temperature also depends on the presence of a contactless zone, which contributes to an increase in heat transfer from the billet to the rolls. The results of the research were used to develop the technology for the production of welding wire from $\mathrm{Al}-\mathrm{Mg}$ system alloys.
\end{abstract}

\section{Introduction}

To study the shape and temperature-speed conditions of the process of combined rollingextruding (CRE) [1,2], computer simulation was carried out in the Deform-3D software package to produce round bars from an $\mathrm{Al}-\mathrm{Mg}$ system (AMg6) on units, technical parameters of which are given in table. 1 .

Table 1 - Data for the calculation and simulation of combined machining

\begin{tabular}{|l|c|c|c|c|}
\hline \multirow{2}{*}{ Value } & \multicolumn{4}{c|}{ Unit name } \\
\cline { 2 - 5 } & CRE-200 & CRE-400 & CCRE-2.5 & CCRE-4 \\
\hline Roll diameter with a protrusion $D_{1}, \mathrm{~mm}$ & 214 & 385 & 462 & 428 \\
\hline Roll diameter with groove $D_{2}, \mathrm{~mm}$ & 164 & 385 & 394 & 428 \\
\hline Minimum caliber height $h, \mathrm{~mm}$ & 7 & 9 & 10 & 19 \\
\hline Roll rotational speed $\omega, \mathrm{rpm}$ & $5-14$ & $0-5$ & $0-6$ & $0-15$ \\
\hline Average roll diameter $D_{0}, \mathrm{~mm}$ & 189 & 385 & 428 & 428 \\
\hline Caliber width $b, \mathrm{~mm}$ & 15 & 22,5 & 22 & 42 \\
\hline
\end{tabular}




\begin{tabular}{|l|c|c|c|c|}
\hline Initial height of the workpiece $h_{0}, \mathrm{~mm}$ & 14 & 20 & 20 & 42 \\
\hline Initial width of the workpiece $b_{0}, \mathrm{~mm}$ & 14 & 20 & 20 & 40 \\
\hline Die mirror height $h_{d}, \mathrm{~mm}$ & 20 & 27,4 & 25 & 31 \\
\hline The diameter of the press product $d, \mathrm{~mm}$ & $7-9$ & 9 & $9-12$ & $9-15$ \\
\hline
\end{tabular}

Despite the large number of works devoted to the study of the properties and machining technologies of alloys Al-Mg system [3-11], obtaining long-dimensional deformed semi-finished products from these alloys is an urgent task for production.

Methods of carrying out researches

To simulate the process, it is necessary to know the rheological characteristics of the alloy of a given chemical composition (Table 2). They were determined according to the hot-twist test method developed at the Department of Metal Forming of the School of Non-Ferrous Metals and Materials Science SFU [12].

Table 2 - The chemical composition of the investigated alloy

\begin{tabular}{|c|c|c|c|c|c|c|c|c|}
\hline $\mathrm{Al}$ & $\mathrm{Fe}$ & $\mathrm{Si}$ & $\mathrm{Cu}$ & $\mathrm{Zn}$ & $\mathrm{Mg}$ & $\mathrm{Be}$ & $\mathrm{Ti}$ & $\mathrm{Mn}$ \\
\hline $91.1-93.68$ & 0.4 & 0.4 & 0.1 & 0.25 & $5.8-6.8$ & $0.0002-0.005$ & $0.02-0.1$ & $0.5-0.8$ \\
\hline
\end{tabular}

The results of these studies are the curves of the dependence of the deformation resistance on temperature $(T)$, the degree $(\varepsilon)$ and speed of deformation $(\xi)$, presented in the form of graphs in fig. 1.
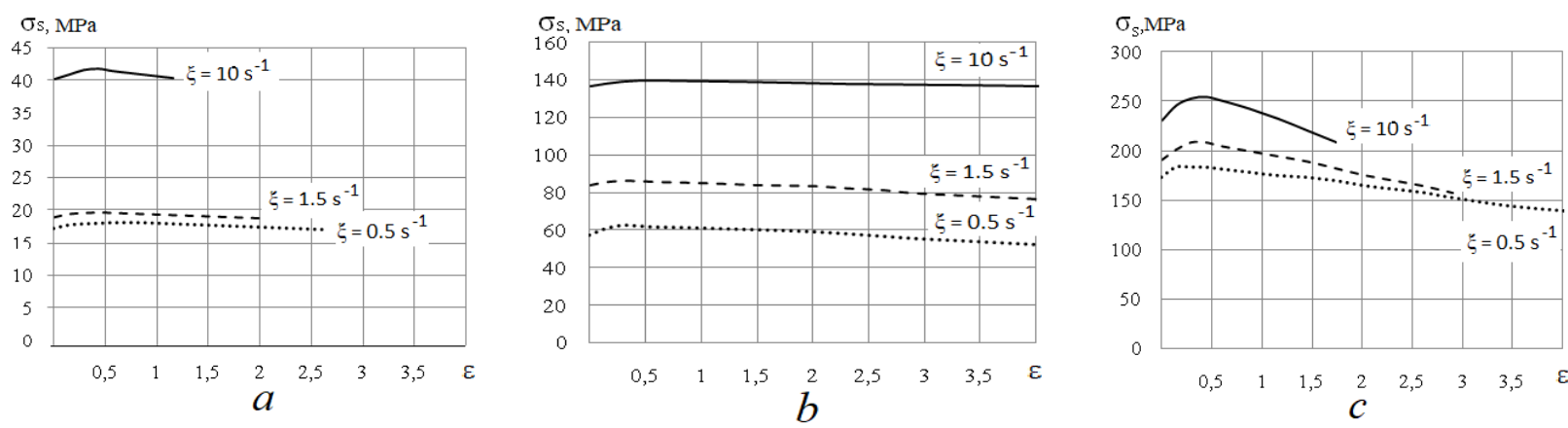

Fig. 1. The dependence of the deformation resistance $\sigma_{s}$ for alloy $\mathrm{AMg} 6$ on the degree of deformation $\varepsilon$, strain rate $\xi$ and temperature $T: a-550{ }^{\circ} \mathrm{C} ; b-450{ }^{\circ} \mathrm{C} ; c-320{ }^{\circ} \mathrm{C}$;

In the MathCad software package they were approximated and the coefficients for the equation below were calculated, and the calculation error does not exceed $2 \%$.

$$
\sigma_{s}=a_{0} \exp ^{a_{1} T} \exp ^{a_{2}} \exp ^{a_{3} / \varepsilon}(1+\varepsilon) a_{4}^{a_{4} T} \exp ^{a_{5} \varepsilon_{\xi} a_{6} T}
$$

where $a_{0}=2.023 \cdot 10^{3}, a_{1}=-7.224 \cdot 10^{-3}, a_{2}=0.022, a_{3}=-4.792 \cdot 10^{-5}, a_{4}=506 \cdot 10^{-4}, a_{5}=-0.165, a_{6}=$ $3.931 \cdot 10^{-4}$ - rheological coefficients, $T$ - temperature, ${ }^{\circ} \mathrm{C} ; \varepsilon-$ deformation degree; $\xi-$ strain rate, $\mathrm{s}^{-1}$.

In order to determine the range of changes in the energy-power parameters of the CRE process, the forces acting on the rolls $\left(P_{r}\right)$ and the matrix $\left(P_{d}\right)$ were calculated (Table 3$)$. Analysis of the calculated data shows that for a caliber with dimensions in the minimum section of $7 \times 15$ $\mathrm{mm}$, even at a temperature of $400{ }^{\circ} \mathrm{C}$, the force on the rolls does not exceed $360 \mathrm{kN}$, and the force on the die is $350 \mathrm{kN}$, while with increasing drawing ratio, their values increase. An increase in temperature to $550{ }^{\circ} \mathrm{C}$ leads to a decrease in the force almost by a factor of $2-3$. The maximum values of the energy-power parameters for the AMg6 alloy were obtained by combined rolling-extrusion at the experimental industrial unit CCRE-4 with the maximum dimensions of the caliber. It should also be noted that the calculation for large degrees of 
deformation $(\mu=14.3)$ for the temperature $T_{b}=550{ }^{\circ} \mathrm{C}$ was not made, since for these process parameters no data on the rheological characteristics were obtained due to the destruction of the samples (Fig. 1).

\section{Results and its discussion}

Analysis of the power parameters of the CRE with significant degrees of deformation $(\mu=14.3)$ and low temperature of the workpiece $\left(T_{b}=400{ }^{\circ} \mathrm{C}\right)$ showed that with these parameters they are significantly lower than the limiting pressing forces on hydraulic presses used to machining the alloy under study. Therefore, the energy consumption for metal deformation with combined processing is 5-10 times lower, which once again confirms the positive influence of active friction forces during combined rolling-pressing [1,2].

The calculations showed that it is necessary to carry out the process at elevated temperatures of the workpiece (up to $550{ }^{\circ} \mathrm{C}$ ) and relatively low strain rates $\left(\xi=0.5-1.5 \mathrm{~s}^{-1}\right.$ ), which leads to lower power parameters. The processing temperature must be in such a range that, at a given strain rate, prevents the formation of temperature cracks on press products. With an increase in the diameter of the rolls and the size of the caliber, the energy-power parameters of the combined machining increase significantly, therefore it is necessary to ensure high strength of the rolls and extruding instruments.

Table 3 - The calculated values of the power parameters of the combined processing of $\mathrm{AMg} 6$ alloy on the installations of combined machining

\begin{tabular}{|c|c|c|c|c|c|c|c|}
\hline & & \multicolumn{3}{|c|}{$T_{b}=400^{\circ} \mathrm{C}$} & \multicolumn{3}{|c|}{$T_{b}=550^{\circ} \mathrm{C}$} \\
\hline & & $\mu=4.3$ & $\mu=7.7$ & $\mu=14.3$ & $\mu=4.3$ & $\mu=7.7$ & $\mu=14.3$ \\
\hline \multicolumn{8}{|c|}{ Unit CRE-200 } \\
\hline \multirow{2}{*}{$\xi=0.5 \mathrm{~s}^{-1}$} & $P_{r, \mathrm{kN}}$ & 215.47 & 238.37 & 251.38 & 61.05 & 68.68 & - \\
\hline & $P_{d, \mathrm{kN}}$ & 143.25 & 187.85 & 239.85 & 40.59 & 54.13 & - \\
\hline \multirow{2}{*}{$\xi=1.5 \mathrm{~s}^{-1}$} & $P_{r, \mathrm{kN}}$ & 298.07 & 331.29 & 359.12 & 68.23 & 72.72 & - \\
\hline & $P_{d, \mathrm{kN}}$ & 198.16 & 261.08 & 342.64 & 45.36 & 57.31 & - \\
\hline \multicolumn{8}{|c|}{ Unit CCRE-2.5 } \\
\hline \multirow{2}{*}{$\xi=0.5 \mathrm{~s}^{-1}$} & $P_{r}, \mathrm{kN}$ & 444.09 & 491.27 & 518.10 & 125.82 & 141.55 & - \\
\hline & $P_{d, \mathrm{kN}}$ & 201.33 & 264.48 & 337.93 & 57.04 & 76.21 & - \\
\hline \multirow{2}{*}{$\xi=1.5 \mathrm{~s}^{-1}$} & $P_{r}, \mathrm{kN}$ & 614.32 & 682.78 & 740.15 & 140.63 & 149.88 & - \\
\hline & $P_{d,} \mathrm{kN}$ & 278.50 & 367.58 & 482.76 & 63.75 & 80.69 & - \\
\hline \multicolumn{8}{|c|}{ Unit CRE-400 } \\
\hline \multirow{2}{*}{$\xi=0.5 \mathrm{~s}^{-1}$} & $P_{r, \mathrm{kN}}$ & 522.67 & 578.20 & 609.78 & 148.09 & 166.60 & - \\
\hline & $P P_{d}, \mathrm{kN}$ & 274.63 & 358.69 & 455.67 & 77.81 & 103.35 & - \\
\hline \multirow{2}{*}{$\xi=1.5 \mathrm{~s}^{-1}$} & $P P_{r} \mathrm{kN}$ & 723.03 & 803.60 & 871.11 & 165.51 & 176.40 & - \\
\hline & $P P_{d}, \mathrm{kN}$ & 379.90 & 498.52 & 650.95 & 86.96 & 109.43 & - \\
\hline \multicolumn{8}{|c|}{ Unit CCRE-4 } \\
\hline \multirow{2}{*}{$\xi=0.5 \mathrm{~s}^{-1}$} & $P_{r, \mathrm{kN}}$ & 1109.31 & 1227.17 & 1294.19 & 314.30 & 353.59 & - \\
\hline & $P_{d}, \mathrm{kN}$ & 629.18 & 826.14 & 1054.39 & 178.27 & 238.04 & - \\
\hline \multirow{2}{*}{$\xi=1.5 \mathrm{~s}^{-1}$} & $P_{r, \mathrm{kN}}$ & 1534.54 & 1705.56 & 1848.84 & 351.28 & 374.39 & - \\
\hline & $P_{d}, \mathrm{kN}$ & 870.37 & 1148.19 & 1506.27 & 199.24 & 252.04 & - \\
\hline
\end{tabular}

Having established the possibility of the implementation of the CRE process, and determining the range of variation of technological parameters, conducted its computer simulation. The following data was chosen as the initial data and boundary conditions for modeling: the material of the workpiece is an aluminum alloy, the material of the rolls and the matrix is tool steel; billet material isotropic; the conditions of contact interaction between the workpiece and the rolls were accepted according to the Siebel law with the friction index at the metal deformation in the rolls $\psi_{r}=0.9$ and on the die $\psi_{d}=0.3$; friction on the contact of the rolls and the die were not taken into account; relative reduction during rolling $50 \%$; the initial temperature of the workpiece $T_{b}=400-550{ }^{\circ} \mathrm{C}$, heat exchange with the environment and the tool; 
the initial temperature of the die $\left(T_{d}\right)$ and of the rolls $\left(T_{r}\right)$ varied from 100 to $200{ }^{\circ} \mathrm{C}$, and heat exchange with the environment and the workpiece takes place; the number of finite elements into which the workpiece is divided was 32 thousand pieces.

To analyze the shape and flow of the metal in the process of deformation, the deformation zone was divided into three characteristic zones: rolling, repressing and extruding. The picture of the metal flow in the deformation process on the CRE-200 unit is shown in Fig. 2. The models obtained make it possible to establish that at the moment of capture by the rolls, the billet is bent toward the roll with a larger diameter, and after passing through the rolling zone, it begins to bend toward the roll with a groove (smaller diameter), bounding it. Next, the workpiece reaches the die, and the process of repressing the metal begins in the working part of the caliber formed by the rolls and the die, partially squeezing into the calibrating hole of the die. After the gauge is completely filled in front of the die, the process of metal outflow begins with the formation of a press product according to the shape and dimensions of the gauge hole of the die. A feature of the change in the alloy under study in the CRE is that with a drawing ratio $\mu=$ 3.7 and a strain rate $\xi=0.78 \mathrm{~s}^{-1}$, the steady extruding process takes place without completely filling the deformation zone from the roll with a large diameter. An increase in drawing ratio or strain rate leads to a decrease in the contactless zone or to its absence.
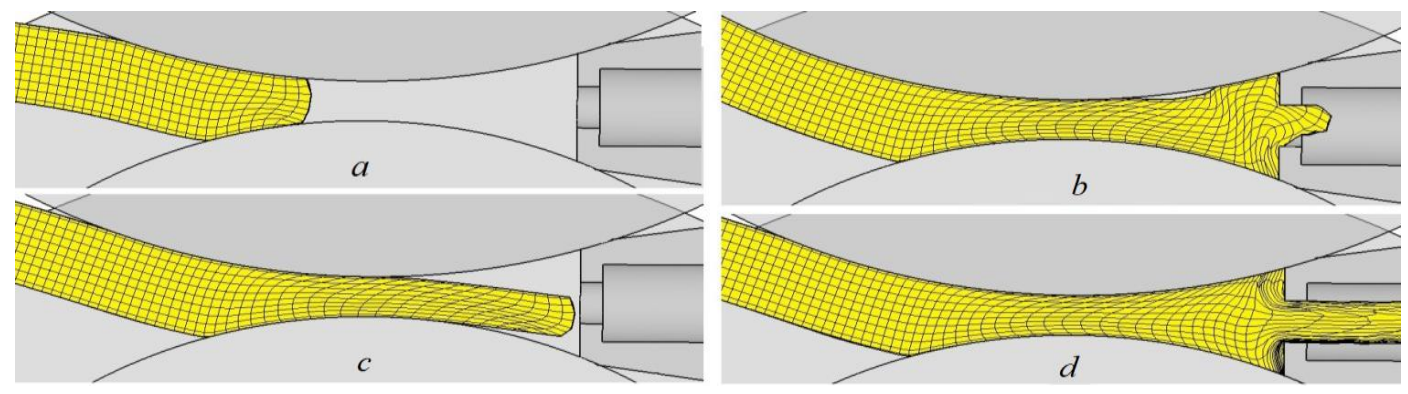

Fig. 2. Forming metal in the deformation zone during CRE: $a$-metal capture stage, $b$ - rolling stage, $c$ - repressing stage, $d$-steady extruding process

Fig. 3 presents a general view of press residues obtained in the model (Fig. 3 a, b) and physical (Fig. 3 c, d) experiment for the AMg6 alloy. On the press residues, zones of contact of the surface of the rolls with the workpiece and the contactless zone on the roll side with a large diameter (protrusion) are clearly pronounced.

An important factor influencing the performance and conditions of a stable process of rolling-extruding is the temperature in the center of plastic deformation and the extruded profile. Fig. 4 shows the nature of the temperature change in the deformation zone during the machining of AMg6 alloy. Change in the temperature of the workpiece from $400{ }^{\circ} \mathrm{C}$ to $550{ }^{\circ} \mathrm{C}$ has an effect on the temperature of the profile coming out of the die within $20-40{ }^{\circ} \mathrm{C}$, an increase in the strain rate from $\xi_{1}=0.78 \mathrm{~s}^{-1}$ to $\xi_{2}=1.57 \mathrm{~s}^{-1}$ per $100-150{ }^{\circ} \mathrm{C}$, and when increasing drawing ratio from $\mu$ $=3.7$ to $\mu=11.8$ to $40-50{ }^{\circ} \mathrm{C}$. Thus, it is possible to choose the processing rate of the alloy under study, which, with the required drawing ratio, makes it possible to assign a temperature of the press product not exceeding the critical one (the onset of temperature cracking) [4].

Throughout the length of the deformation zone, the inner layers of the billet have a higher temperature. The temperature of the metal decreases to the intermediate zone with the maximum crimping of the billet and the repressing zone, but later, due to the large drawing ratio, deformation heat is released during extruding and the temperature begins to rise. The temperature distribution at different drawing ratio is different. Since the drawing ratio of $\mu=3.7$ does not completely fill the deformation zone, the cooling of the billet from the contactless area does not occur, therefore, the temperature of the billet from the side of the roll with a protrusion is slightly higher than from the side of the roll with a groove. Further, in the dead zones of the 
metal in front of the die, a decrease in temperature is observed, and the bar at the exit from the gauge of the die is heated evenly.
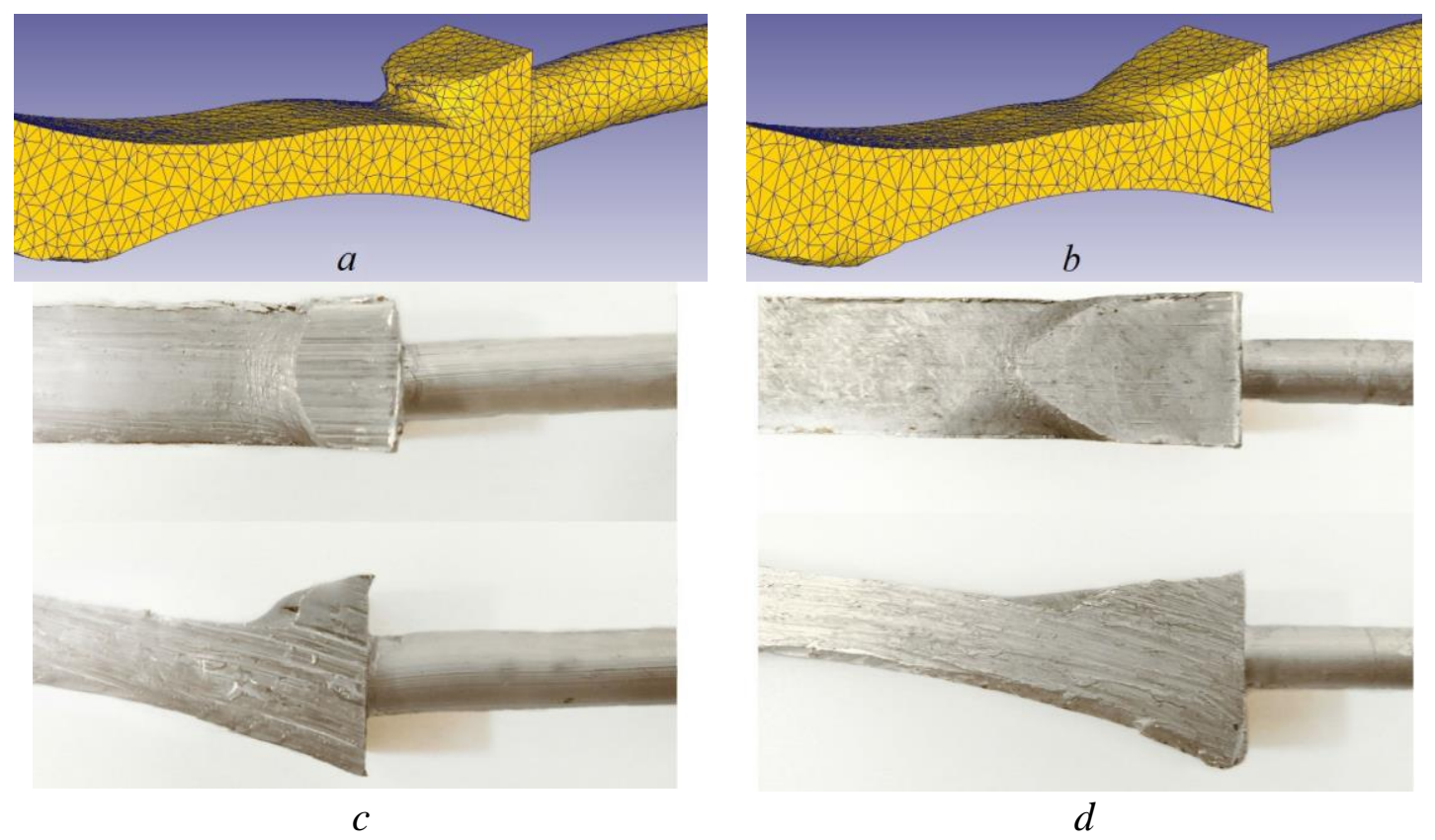

Fig. 3. The results of computer (a, b) and physical (c, d) simulation of the CRE process for the AMg6 alloy at the CRE-200 unit with a drawing ratio $\mu=3.7: a, c-$ strain rate $\xi=0.78 \mathrm{~s}^{-1}$; $b, d-$ strain rate $\xi=1.57 \mathrm{~s}^{-1}$

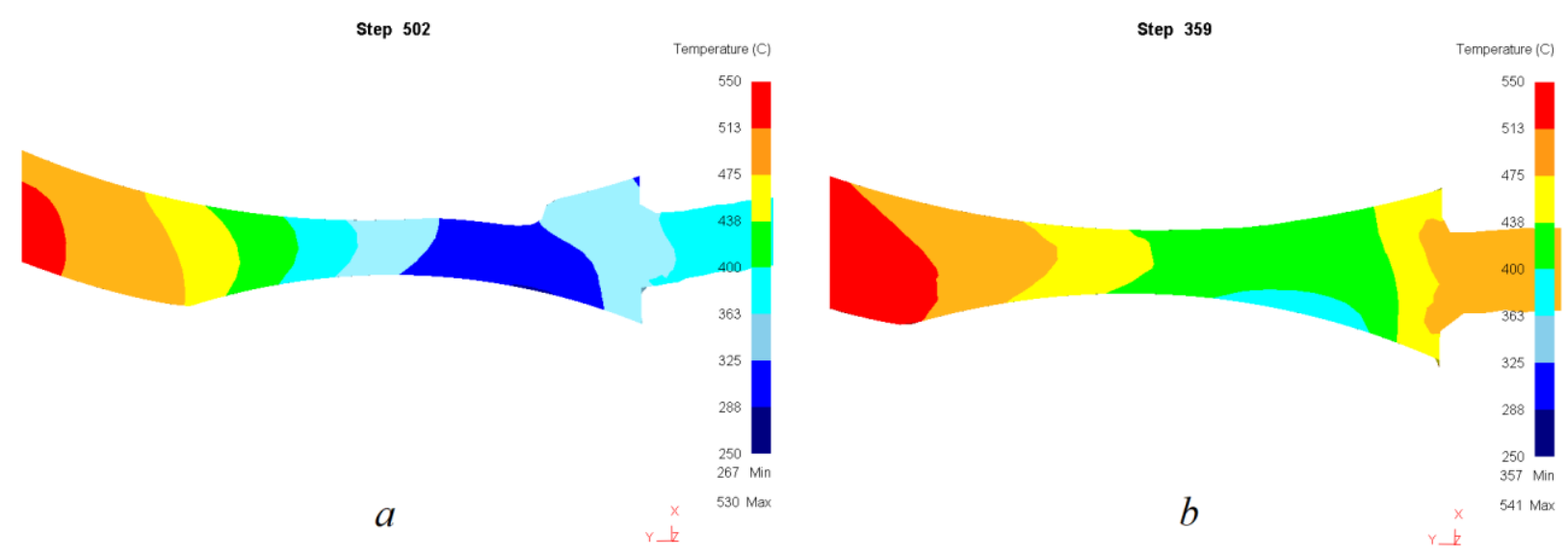

Fig. 4. Temperature distribution over the billet section for AMg6 alloy in a model experiment at the CRE-200 unit with drawing ratio $\mu=3.7$ for a strain rate $\xi_{1}=0.78 \mathrm{~s}^{-1}(a)$ and $\xi_{2}=1.57 \mathrm{~s}^{-1}(b)$

\section{Conclusion}

The analysis of the combined rolling-extrusion process for various aluminum alloys on the basis of the simulation results made it possible to draw the following conclusions. First, the machining of alloys of the Al-Mg system with low strain rates on CRE unit with different rolling diameters of the rolls leads to the formation of a contactless zone in the deformation zone on the side of the roll with a protrusion. This causes an increase in the non-uniformity of deformation and the temperature of the metal and, as a consequence, the possibility of the formation of defects on the surface of the press product in the form of cracks. Secondly, in order to design a technology for the production of press products at the CRE units, it is necessary to take into account the peculiarities of the processed alloy in order to adjust the temperature and speed mode of the installation. For the AMg6 alloy under study, even with slight changes in the strain rate, the metal temperature increases to critical values, which can cause temperature cracks on the surface 
of the press product. Therefore, for the combined machining of this alloy, the following technological parameters are recommended: a roll rotation speed of $2.4 \mathrm{rpm}$, a billet temperature $T_{b}=450{ }^{\circ} \mathrm{C}$, roll and die temperature of $100-200{ }^{\circ} \mathrm{C}$.

\section{References}

[1] Sidelnikov S.B., Lopatina E.S., Dovzhenko N.N. Features of structure formation and metal properties during high-speed crystallization-deformation and modification of aluminum alloys: collective monograph. Krasnoyarsk: SibFU, 2015.

[2] Sidelnikikov S.B., Dovzhenko N.N., Zagirov N.N. Combined and complex methods of machining non-ferrous metals and alloys, M.: MAKS PRESS, 2005.

[3] Loginov Yu.N. Extruding as a method of intensive deformation of metals and alloys: a tutorial. Publishing house of the Ural University, 2016.

[4] Loginov Yu.N., Antonenko L.V. Influence of aluminium alloy stress-strain condition in the initial stage of extruding on cracks formation. Publishing house of the Ural University. (2012) 109-112.

[5] Guan R., Tie D., Li Z., An Y., Wang X., Li Q., Chen X. Microstructure evolution and mechanical property improvement of aluminum alloys with high magnesium content during continuous rheo-extrusion. Materials Science and Engineering A. 738 (2018) 31-37.

[6] Chen H., Yu T., Qi Z., Wu R., Wang G., Lv X., Cong F., Hou L., Zhang J., Zhang M. Effect of Minor Er on the Microstructure and Properties of Al-6.0Mg-0.4Mn-0.1Cr-0.1Zr Alloys. Journal of Materials Engineering and Performance. 27(11) (2018) 5709-5717.

[7] Geng S., Jiang P., Shao X., Mi G., Wu H., Ai Y., Wang C., Han C., Chen R., Liu W., Zhang Y. Effects of back-diffusion on solidification cracking susceptibility of Al-Mg alloys during welding: A phase-field study. Acta Materialia. 160 (2018) 85-96.

[8] Mugada K.K., Adepu K. Effect of Minor Er on the Microstructure and Properties of Al$6.0 \mathrm{Mg}-0.4 \mathrm{Mn}-0.1 \mathrm{Cr}-0.1 \mathrm{Zr}$ Alloys. International Journal of Advanced Manufacturing Technology. 99(5-8) (2018) 1553-1566.

[9] Qi Z., Qi B., Cong B., Zhang R. Microstructure and mechanical properties of wire + arc additively manufactured Al-Mg-Si aluminum alloy. Materials Letters. 233 (2018) 348-350.

[10]Ding Q., Zhang, D., Zuo J., Hou S., Zhuang L., Zhang J. The effect of grain boundary character evolution on the intergranular corrosion behavior of advanced Al-Mg-3wt\% $\mathrm{Zn}$ alloy with $\mathrm{Mg}$ variation. Materials Characterization. 146 (2018) 47-54.

[11]Tang K., Du Q., Li Y. Modelling microstructure evolution during casting, homogenization and ageing heat treatment of $\mathrm{Al}-\mathrm{Mg}-\mathrm{Si}-\mathrm{Cu}-\mathrm{Fe}-\mathrm{Mn}$ alloys. Calphad: Computer Coupling of Phase Diagrams and Thermochemistry. 63 (2018) 164-184.

[12] Grishchenko N.A., S.B. Sidelnikov, I.Yu. Gubanov [and others]. Mechanical properties of aluminum alloys: monograph. Krasnoyarsk: SibFU, 2012. 